\title{
CAD-CAM Technology: A literature Review
}

Mohammed A. Abdulla BDs, MSc (Lec.)

Hala Khuder Ali

BDs, MSc (Assist. Lec.)

\section{Raghad S Jamel}

BDs, MSc (Assist. Lec.)

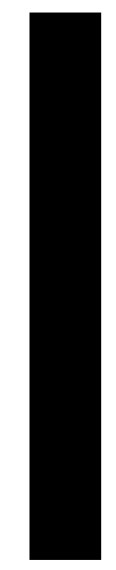

\author{
Department of Prosthetic Dentistry \\ College of Dentistry, University of Mosul \\ Department of Prosthetic Dentistry \\ College of Dentistry, University of Mosul \\ Department of Conservative Dentistry \\ College of Dentistry, University of Mosul
}

\begin{abstract}
الخلاصة

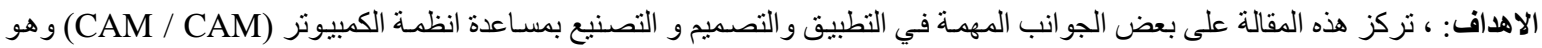

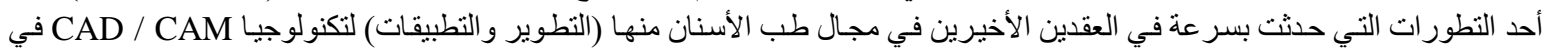

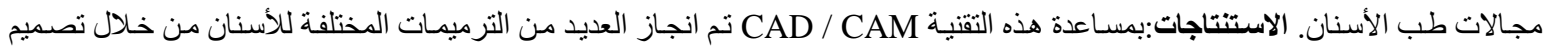

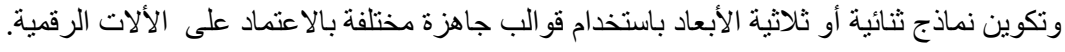

\begin{abstract}
Aims: this article focuses on some important aspects related to a CAD/CAM technology including: applications, designing, and construction by the use of computerized controlling machines that developed very quickly in the last two decades. Conclusions: CAD/CAM technology attains different dental restorations through designing and milling processes of a two dimensional or three dimensional models using different ready blocks by numerical controlled machines.
\end{abstract}

Key words: CAD-CAM, Technology, Software

Abdulla MA., Ali H Kh., Jamel RS . CAD-CAM Technology: A literature Review. Al-Rafidain Dent J. 2020 ;20 (1): 95-113.

DOI: $10.33899 /$ rden.2020.164542

Received: 11/1/2020 Sent to Referees: 15/1/2020 Accepted for Publication: 29/4/2020

\section{INTRODUCTION}

Computer aiding design /computer aiding manufacturing (CAD-CAM) is a currently a developed scope of dental restorations and prosthodontics rehabilitation through the use of $\mathrm{CAD} / \mathrm{CAM}$ system to create an appropriate design and fitness of different dental restorations like zirconium crown, fixed bridges, dental (veneers, inlays, onlays), dental implant restorations, orthodontic appliances, and removable dentures (complete and/or partial). ${ }^{(1)}$ During the 20 th century, both dental technologies and materials were used for the fabrication of dental prosthesis progressed quickly. In the past 25 years, this system has 
become more popular to be used over the world.

(2). The first system introduced was developed by

Duret et al. in 1971, but was not widely used because of the absence of fitness and accuracy of digitizing, computer power , equipments, and materials. ${ }^{(3)}$

The next decade in 1989, in Germany CEREC $^{\circledR}$ system was developed by Mormann \& Brandestinni in Zurich, Switzerland. The name CEREC $^{\circledR}$ means Ceramic RE-Construction. CEREC $^{\circledR}$ was responsible for the exponential increase in CAD/CAM technology throughout the world. ${ }^{(4)}$ Nowadays, this system is widely used in all the branches of prosthetic treatments and not only be designed by the aid of computer, but also machined (milled) with high accuracy and precision. ${ }^{(5)}$ Due to the demand to use safe and cosmetic materials needed for the patients, a newly zirconium materials have been produced as esthetic restorative materials. ${ }^{(6,7)}$

From 1970s to 1980s, a rapid development in"computer-assisted" manufacturing technology in different fields of industries, researches, dental CAD-CAM technology occurred in the worldwide including dental Japanese institutes. $^{(8,9)}$

\section{- Development of the dental CAD/CAM systems:}

A new products are available as a digital impression in dental offices: [CEREC $\mathrm{AC}^{\circledR}$ (Sirona, Charlotte, NC, USA)] Figures $(1,2)$, iTero (Cadent, Carlstadt, NJ, USA), E4DDentist (D4D -Technologies, Richardson, TX, USA), and ((Lava COS ,3M ESPE, St Paul, MN,USA)). Every system employs different techniques to produce the digital images. CEREC -1 in the year 1986 is introduced as the first system, then CEREC- 2 as the second system in the year 1994, while the CEREC-3 is consider as the third system in the year 2000. A camera has used in Sirona ${ }^{\circledR}$ dental system to take serial pictures that are collected together within software. The E4D (D4D TECH) ${ }^{\circledR}$ captured several images, by using a red laser beam to reflect the tooth structure as a negative replica and needs the application of spray powder within limited cases. The applied spray powder of the tooth seems to be quick and simple, taking few seconds. The removal of the powder is easy by washing. The iTero ${ }^{\circledR}$ dental system uses a camera with a small probe that touches all tooth surfaces (without spray powder ) to give a perfect focal length. The LAVA ${ }^{\circledR}$ Chair side oral scanner (LAVA COS, 3M ESPE) operates by using a continuous video stream of the teeth. A new (CEREC and LAVA) ${ }^{\circledR}$ systems need spray powder to record teeth topography. ${ }^{(10)}$ 

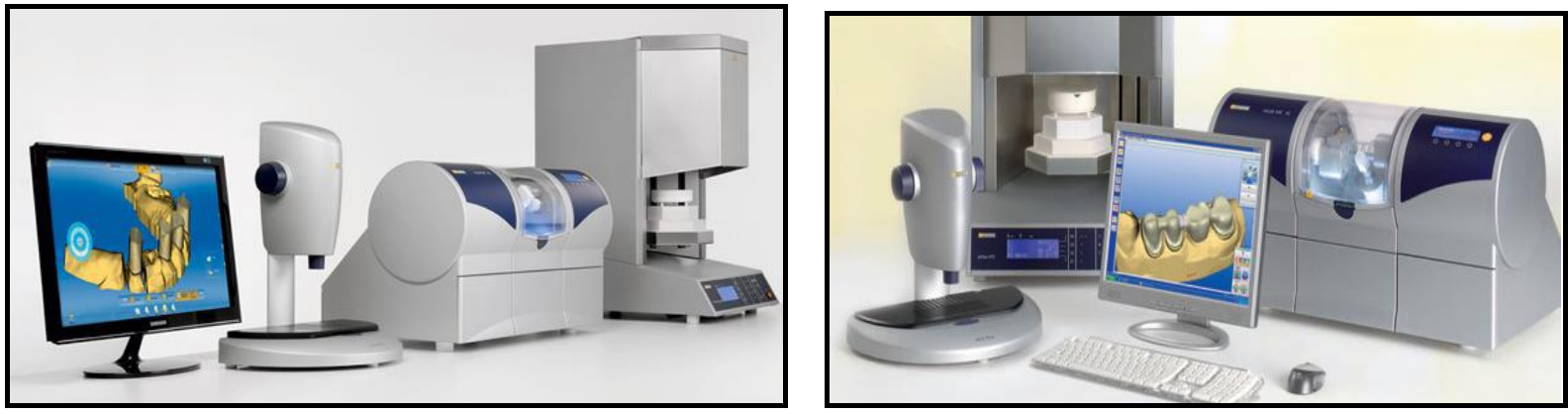

Figure (1): CEREC $^{\circledR} 3 \mathrm{D}$ computerized ${ }^{(11)}$

Figure (2): Sirona, 3M Dental CAD/CAM System ${ }^{(11)}$

The first person who produced the dental CAD-CAM system was Dr. Duret. ${ }^{(12)}$ In 1971 Dr. Duret started to construct crowns having the anatomical shape of the occlusal surfaces by using an optical scanned impression of the abutment teeth inside the mouth followed by design and milling crowns using milling machine controlled by computerized system. Later Dr. Duret developed the Sopha ${ }^{\circledR}$ system, which play important role subsequent advancement of the world's (CAD / CAM) dental system.

Dr. Moermannn is considered as the second who developed the CEREC $^{\circledR}$ system ${ }^{(8)}$; he tried to use a new clinical technique in the chair side dental office and pictured the prepared cavity using an intra-oral camera, then designed and milled an inlay restoration from a ceramic blank using a portable milling machine. The major benefit of this system is the production of ceramic restorations on the same day that makes the system spread rapidly as "CAD/CAM" term to the dental profession.

Dr. Andersson is considered as the third who developed the Procera ${ }^{\circledR}$ system. $^{(13)}$ At the begining of 1980s, nickel-chromium alloy used as a substitute to gold bullion due to the high gold prices. However, an allergy to the metal became a problem and the use of titanium alloy was indicated. Since the precision in casting of titanium have a limitation in the using due to its difficulty in the manipulation. Dr. Andersson. tried to fabricate tooth-copings made from titanium and introduced (CAD/CAM) system into the process of tooth veneered restorations. $^{(14)}$

A number of institutes in Japan began researches with developing dental "CAD-CAM" systems in the latter mid of the 1980s. ${ }^{(15,16,17,18)}$ Many CAD / CAM systems were available in the Japanese markets. The CAD-CAM manufacturing systems for dentistry was shown in Figure (3): 
Abdulla MA., Ali H Kh., Jamel RS

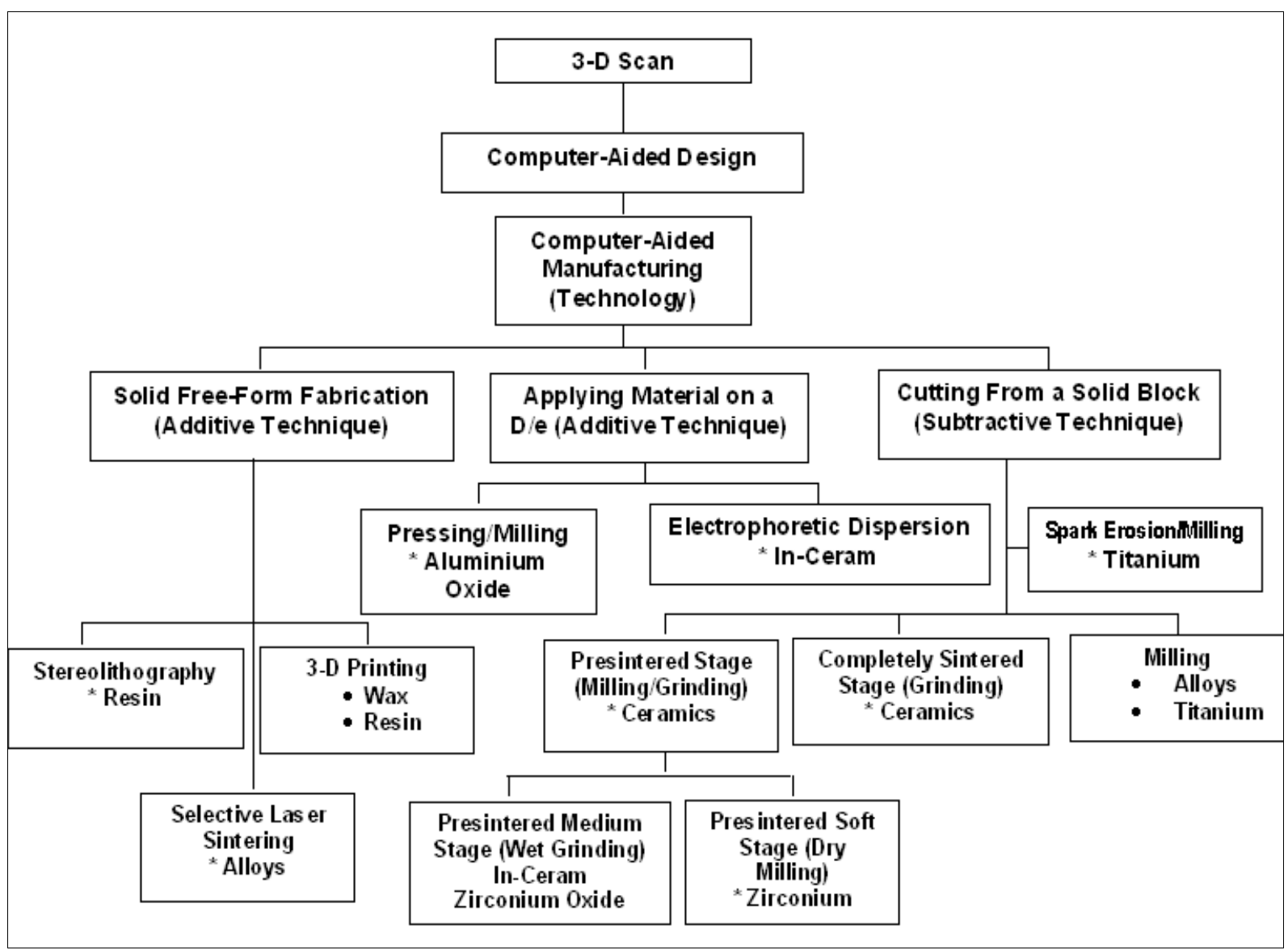

Figure (3): Overview of CAD/CAM manufacturing systems for dentistry ${ }^{(19)}$

\section{- Phases (Components) of the system ${ }^{(20,21)}$}

Three Components (phases) are mainly exist by the use of this system including:

The first Component is the scanning phase (computer surface digitization), this be divided into two options:

1. Optical scanning .

2. Mechanical scanning.
1. Optical camera: This scanning device is based on the collection of 3-D structures called "triangulation procedure". Here, the light source with the receptor unit presented in a specific angle in relationship to each another. With the aid of this angle a 3-D data calculated by computer from the image on the receptor unit. White light or laser beam can be used as a source of lighting Figure (4). 


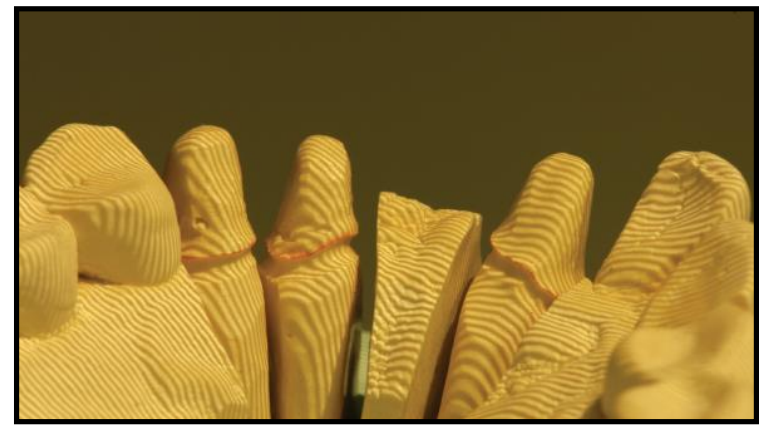

Figure (4): White light projector pattern by optical scanner ${ }^{(20)}$

The following examples of optical scanners on the dental marketing fields: ${ }^{(20)}$

- Lava Scan ST, 3M ESPE, scanning source $=$ white light

- Everest Scan, KaVo, scanning source= white light.

- es1, etkon. scanning source= laser beam.

2. Mechanical scanning devices: For this type of scanning device, the poured cast is mechanically scanned (read)line-by-line by the use of a ruby ball and the object threedimensionally was measured and characterized by a high quality of scanning accuracy. Then, all digital data collection would be designed then milled. ${ }^{(22,23)}$ This technique is somewhat complicated, more expensive and time consuming compared to other scanner (Figure $5)$.
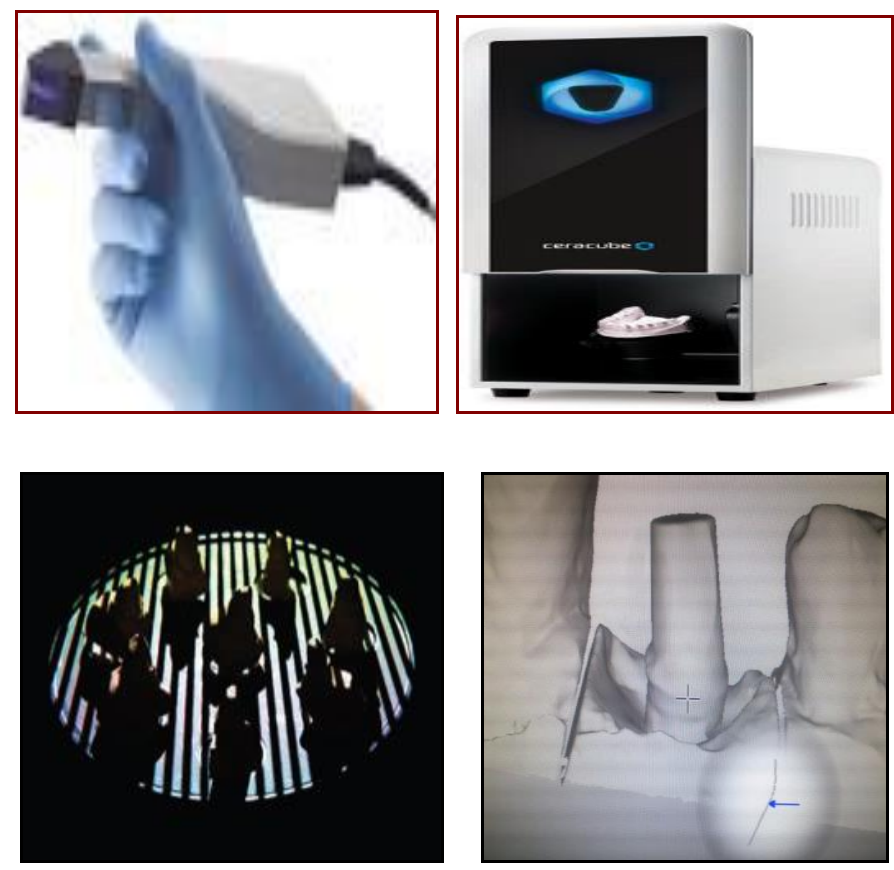

Figure (5): Scanning devices 
The second component is the designing digitized data is designed within the computer phase. After a three dimensional image is followed by the construction programs Figure captured by the use any of scanning techniques,

3-D image processing is finished and the

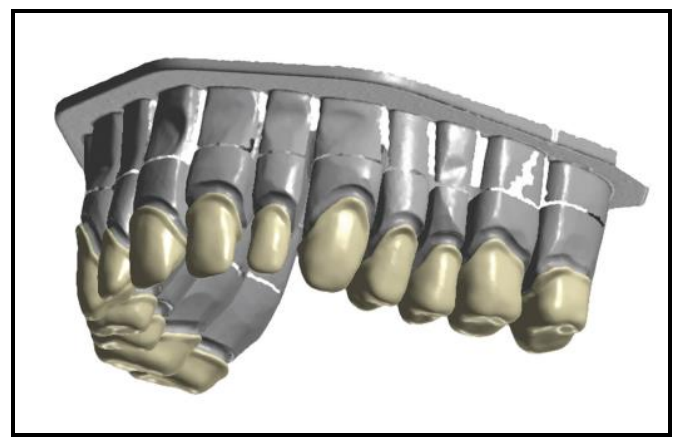

Figure (6): Three dimensional images ${ }^{(20)}$

Finally, surface smoothing, error product by milling machine with the aid of elimination and undesirable undercuts were computer using a high quality diamond (disks blocked at this stage. Different design of or burs) which cut the restoration from ingots . restorations are done using specific CAD This process is known as "substractive method software, which in turn send orders to the CAM unit to fabricate restoration through a milling machine.

The Third and final component is systems combined the two techniques manufacturing phase. This step transforms the digital data of the restoration into a physical

Other method is "additive", e.g. selective laser sintering or rapid prototyping so waste and excess of materials not present. Other "additive and substractive methods". Figure (7).

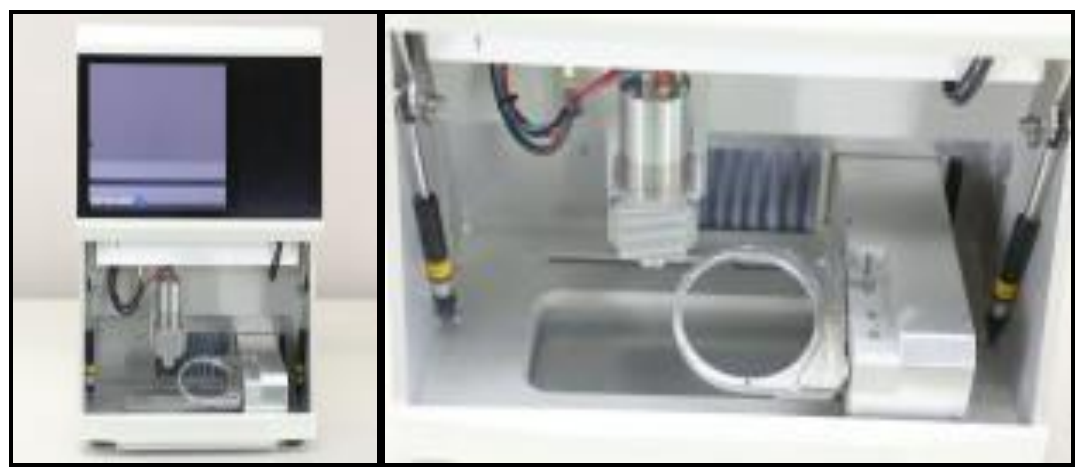

Figure (7): Milling machine 
Milling Processing devices: ${ }^{(20)}$

The digitizing data designed with a specific CAD software are transfered to a physical product (strips) for the CAM- processing phase then transformed to the milling machine. According to the number of milling axes manufactured devices can be divided into:
a. 3-axis milling devices
b. 4-axis milling devices
c. 55-axis milling devices.

\section{a. Three-axis milling:}

Three-axis milling has a degree movement a path of three axial directions denoted by (X,Y, $\mathrm{Z}$ values) Figure (8). Three-axis milling machine can also turn the component in $180^{\circ}$ in the cycle of milling process. The advantages of this milling device are short time of milling procedure, easily control, less cost compared with other type of milling. Examples of 3three- axis devicces: "inLab (Sirona) ${ }^{\circledR}$, Lava $^{\circledR}(3 \mathrm{M}$

ESPE), Cercon ${ }^{\circledR}$ brain (DeguDent)".

\section{b. Four-axis milling:}

In this type, the tension bridge can also be turned without any limitation during work Figure (8) makes it easy to control bridge fabrication with a long displacement in a vertical direction into the usual mold dimension. The main advantage is saving both milling time and used materials, e.g. Zenoo ${ }^{\circledR}$

"Wieland-Imes".

\section{c. Five-axis milling:}

In addition to 3,4 axes, new rotatable tension bridge and spindle of milling (5-axis) with complex geometries subsections are presented (Figure8). This is indicated in the construction of crown and fixed bridge for inclined abutment teeth "when molar tipped towards the medial plane".

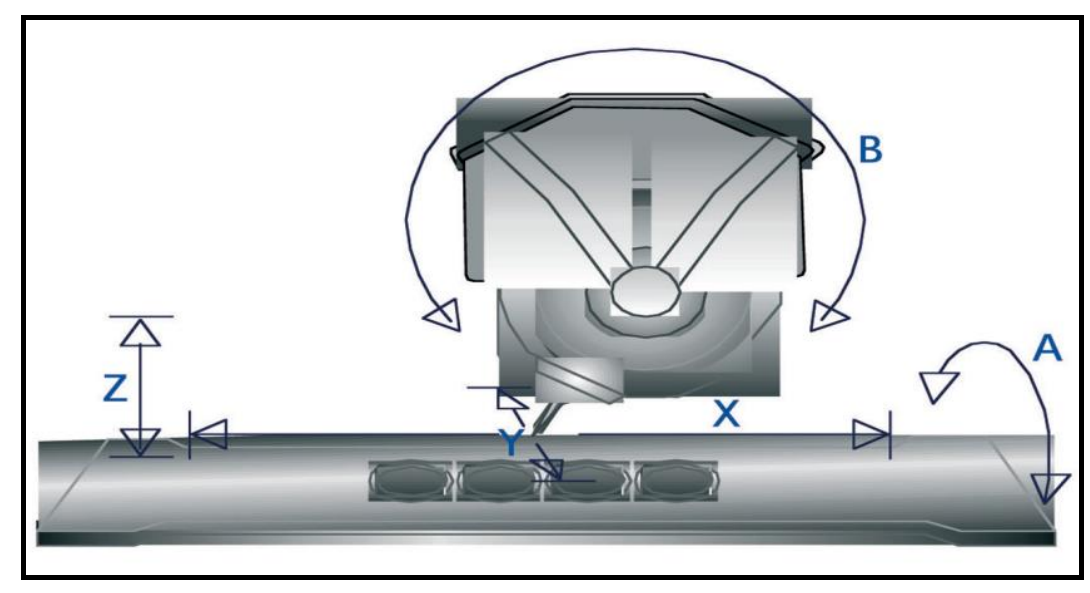

Figure (8): Milling Processing device: (3 axis milling devices include $\mathrm{X}-\mathrm{Y}-\mathrm{Z}$ ); (4 axis milling devices include $\mathrm{X}, \mathrm{Y}, \mathrm{Z}$ and tension bridge $\mathrm{A})$; (5 axis milling devices include $\mathrm{X}, \mathrm{Y}, \mathrm{Z}$, tension bridge A and milling spindle B) ${ }^{(20)}$ 


\section{- Milling variant: ${ }^{(20)}$}

a) Dry field milling: This field of milling is mostly applied to mill $\mathrm{ZrO}_{2}$ blanks (Figure 9) having lower degree of pre-sintering. One of dry milling process recommended by manufacturers is milling a resin material for the construction of different temporary and permanent restorations were designed using CAD-CAM system.

\section{$\underline{\text { Advantages }}$}

1- Low costs are used as a milling procedure.

2- No need for drying of the $\mathrm{ZrO}_{2}$ frame prior to sintering because there is no moisture absorption by the die $\mathrm{ZrO}_{2}$ mold.

\section{Disadvantages:}

Higher shrinkage values where obtained for the frameworks are due to the lower degree of pre-sintering.

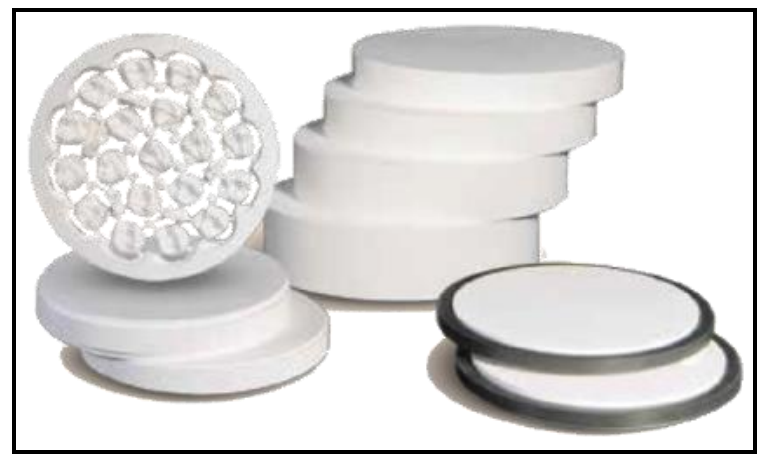

Figure (9): Zirconium oxide blanks

b) Wet field milling: In this process as a for all metal-alloys and glass- ceramic to prevent protection, a spray bath of cooling system damages by heat generation. When $\mathrm{ZrO}_{2}$ applied to reduce overheating within the milled ceramic with high degree of pre-sintering lead to material by the use of diamond or carbide burs minimize the shrinkage factor and less sinter Figure (10). This Wet field milling is indicated distortion.

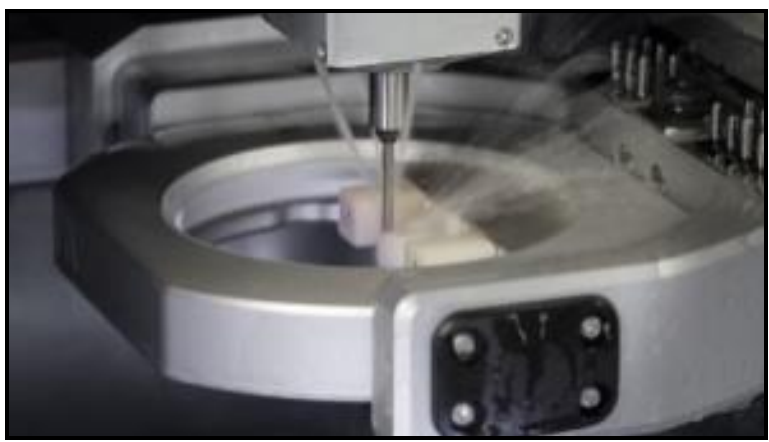

Figure (10): Wet field milling processing 
- Application of CAD-CAM system in dental fields:

\section{a) CAD-CAM application in a dental chair-side :}

Dr. Moermann. succeeded to produce chairside ceramic inlay restoration in a short time by developing the CEREC $^{\circledR}$ system . This system can scan the prepared tooth intra-orally and by selecting efficient materials. The dentist can easily fabricate the restorations and delivered it within a single appointment, but still the anatomical occlusal surface of inlay need to be shaping the fine details. ${ }^{(8,19)}$

Due to the limits to the camera's digitizing accuracy, marginal fitness of the prepared inlay firstly being unsatisfactory . Later on, the developed system become more accepted in most dental clinics when used with a new adhesive luting composite materials make CAD-CAM system more popular within the dental profession. Many reports have been published on the CEREC $^{\circledR}$ system denote that there is a continues improving in both apparatus and software with a satisfactory results. ${ }^{(24,25,26)}$ b) CAD_CAM application in the construction of crown and bridge in dental lab:

Dr. Duet's researches were actively employed to construct crowns and fixed bridge with a fine occlusal anatomical surface using CAD_CAM systems. In 1985, firstly applied the CAD_CAM system as a fabrication system for removable prosthesis using electric discharge machine controlled numerically. ${ }^{(27-31)}$ Then in 1990, researches and progression showed that many of CAD_CAM system under the development to be used for the production of crowns and fixed partial prosthesis practically Figure (11). A stone models or dies of the prepared teeth were scanned by the use of indirect systems within the dental laboratory. These systems are produce copings (cores) which need to be add (build) esthetic-enamel porcelain by dental technician for individualization and making restoration to be more naturally appearance. ${ }^{(19)}$

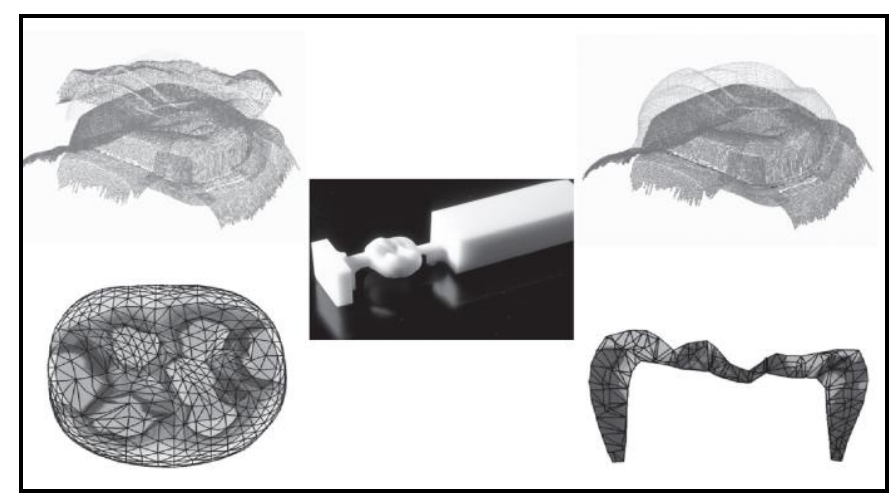

Figure (11): Designing and fabrication of the crown ${ }^{(32)}$ 
c) CAD-CAM application in laboratory work using networks:

Newly a developmental high strength ceramics were used as a framework (core) material for all-ceramic restorations because of their advantages which include: esthetic, compatibility compared with porcelain-fused to metal restorations (PFM). ${ }^{(6,19,33)}$ The enhanced mechanical properties including the flexural strength and fracture resistance. So many materials were marked to be used in the dental field like [Lithium disilicate (empress II ${ }^{\circledR}$ ), glass infiltrated alumina (In Ceram alumina ${ }^{\circledR}$ ), glass infiltrated alumina with stabilized zirconia(Inceram zirconia $^{\circledR}$ ), more dense sintered highpurity alumina (procera ${ }^{\circledR}$ ) and yttria-stabilized tetragonal zirconia polycrystal materials $\left(\mathrm{CERCON}^{\circledR}, \quad\right.$ DCsPrecident ${ }^{\circledR}, \quad$ and $\left.\left.\mathrm{LAVA}^{\circledR}\right)\right]$ were used for cores production of all-ceramic fixed prosthesis . ${ }^{(34-42 .}$ The design and framework production for improved ceramics is practically sensitive compared with conventional dental laboratory work. Recently, a new CAD_CAM system combined with a networked machining center (out sourcing core fabrication) using a network was introduced; where Procera ${ }^{\circledR}$ system was firstly applied as out sourced using a network between dental laboratories on the one hand and a processing centers on the other in (Sweden , USA) to produce a dense high-purity sintered alumina-cores for ceramic crowns. ${ }^{(13,43)}$

\section{-Uses of CAD_CAM technology:}

A- CAD/CAM technology in fixed prosthesis fabrication: ${ }^{(44,45)}$

Around the year 2000, CAD-CAM system start to affect in the production of dental restorations. Titanium was the first metal alloy to be used in dental CAD-CAM in the production of the framework due to its efficient biological and mechanical properties. Milled titanium produced with well-fitting restoration, no $\alpha$-case layer, laser welding, spark erosion. It reduced the costs of fabrication in comparison to other copying materials. Fabrication of crown-bridge restorations using CAD/CAM systems is shown in Figure (12).

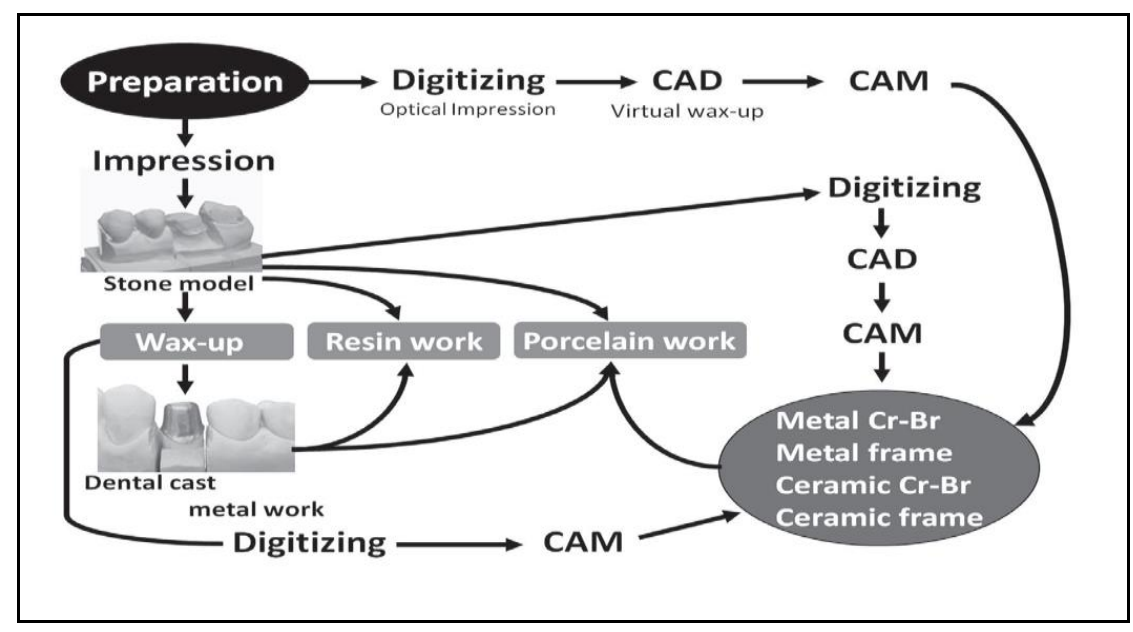

Figure (12): Fabrication of crown-bridge restorations using CAD/CAM systems ${ }^{(32)}$ 
After the abutment teeth are prepared, the first step is taking an impression then model pouring, wax sculpture then metal casting procedure. New technique was investigated and developed by Dr. Duret were these followed steps were summarized with the help of computer-assisted technique so abutment teeth are scanned intra-orally then restorations are designed showed by monitor digitally using a specific designed CAD software based on the numerical data similar to conventional wax-up technique. Restorations finally are milled by using one of the different milling machines available in the dental market. ${ }^{(32)}$ This technique is sensitive because of the limitation of the measuring conditions in the mouth, including superimpose adjacent teeth, gingiva, and salivary interfere lead to a difficulty in the registration of an accurate margin of the prepared abutment. This in turn make the use of the system to fabricate final precision restorations in a critical limitation. ${ }^{(32)}$

While Dr. Moermann worked to produce a ceramic inlay restoration using computerassisted technology and he succeeded. Scanning the prepared inlay cavity was done within the oral cavity using a new specific design of intraoral camera. Design and fabrication of inlays done at the chair-side compact machine. Technically, scanning the prepared inlay cavity was less difficult compared with scanning procedure of prepared crown abutments. ${ }^{(32)}$
After the stone model of the prepared single crown or fixed bridge is digitized (scanned), restorations are designed and fabricated by using one of the different milling machines. Currently, Procera ${ }^{\circledR}$ CAD-CAM systems used mainly in the production of highstrength ceramic frameworks. ${ }^{(32)}$

By using a digital impressions, this will give the benefit for the dentist no need for stock trays, mixed material to be set, disinfecting and cleaning up the impression, time spend to send the impression to the technical laboratory. The CEREC $^{\circledR}$ and E4D devices were combined for designing and milling. This combination the restoration to be finished at the same day. While Lava $^{\circledR}$ COS and iTero devices are designed for image only. ${ }^{(46,47)}$

\section{B- CAD-CAM technology in fabrication of removable partial denture (RPD) framework:}

Fabrication framework of RPD is made

from cobalt chromium (Co-Cr) or commercially pure titanium alloys can be done by using CAD-CAM systems (Figure13). A method to fabricate a removable partial denture framework was explained and designed by (William et al., 2006) Specific CAD-CAM software who designed the framework was built on a three dimensional scan of the patient's model (Figure14). The framework showed an accuracy of fit judged to be comparable to the results obtained by traditional casting methods (Figure 15). ${ }^{(48)}$ 

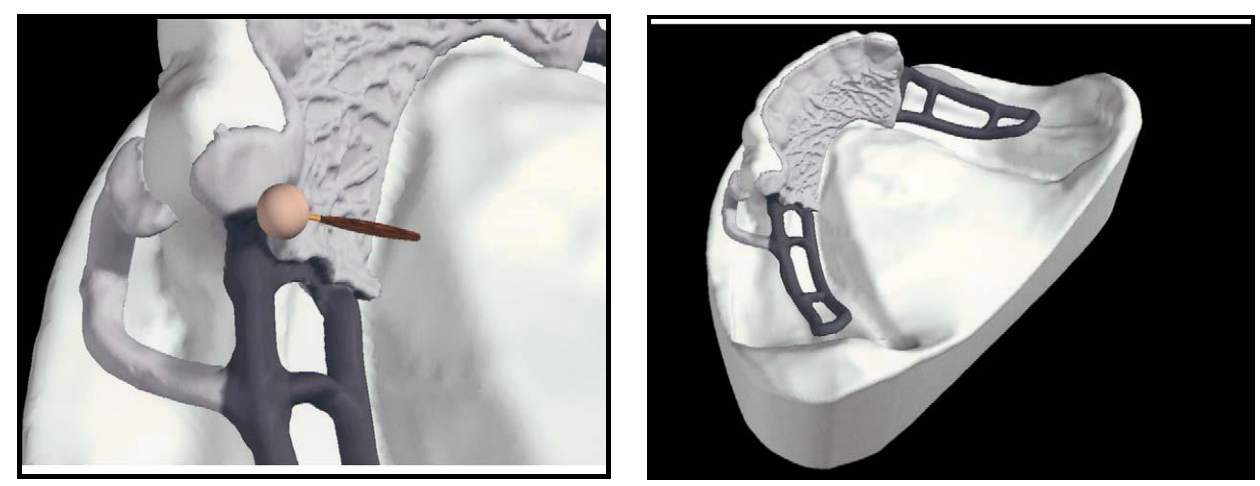

Figure (13): RPD being created using the software CAD CAM system. ${ }^{(48)}$

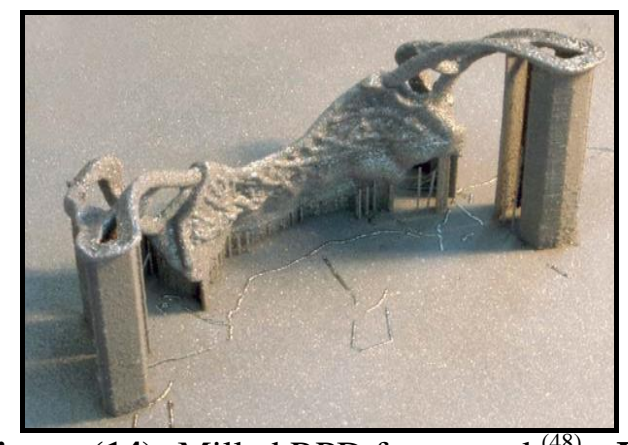

Figure (14): Milled RPD framework

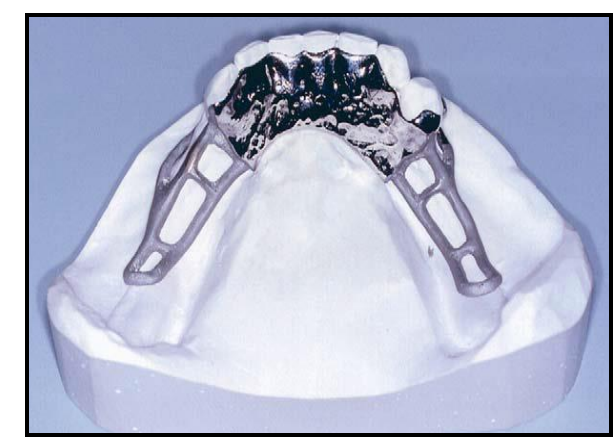

Figure(15): Framework fitting on the cast ${ }^{(48)}$

\section{C- CAD-CAM technology in the fabrication of dental implant:}

A simplified precise and durable implant components were fabricated by the use of CAD/CAM technology. Milling is produced component from durable and aesthetic materials with an excellent fit have been employed in specialized laboratories and attributed in designing of implants. ${ }^{(49,50)}$

Products from CAD/CAM technique are more accurate, no need for fabrication steps such as (waxing, investing, casting procedure, and polishing) than the lost wax/casting technique. Although the degree of fitness of copings is produced by CAD-CAM system within the acceptable range despite little degree of less fitting was reported in relation to the margin of restoration and the internal fitting surface. ${ }^{(51,52)}$

Newly, chair-side implant abutment fabrication can also be achieved by using one of available CAD/CAM (Cerec ${ }^{\circledR}$ system) through intraoral scanning of a prefabricated titanium cylinder then designing and milling a definitive abutment which made from zirconium to the perfect contour. The zirconium abutment was cemented on the prefabricated titanium cylinder. (53)

The use of CAD-CAM titanium abutments have several advantages compared to the traditionally cast custom abutments. Some 
clinicians might be more comfortable with placement of wax denture,and making a conventional impression of the healing placement/insertion of complete dentures. These abutment and then the definitive CAD/CAM clinical and laboratory procedures are mainly abutment to provide the information needed for performed manually. Therefore, it is very fabrication of the definitive restoration. ${ }^{(54)}$

\section{D- CAD/CAM Technology in the fabrication of removable complete dentures:}

Complete dentures are mainly fabricated using conventional methods of clinical and laboratory followed steps. ${ }^{(55)}$ To obtain complete dentures, edentulous patient need several visits to come to the dental clinic, including preliminary impressions, final impressions, recording jaw relations, trial challenging to ensure the quality for the manually designed and fabricated dentures. Moreover, it is difficult to re-use those physical models generated in the process to produce additional complete dentures latter when the patient need them. Computer-aided design and computer-aided manufacturing (CAD/CAM) has emerged as a new approach for the design and fabrication of complete dentures Figure (16). $(57,58)$

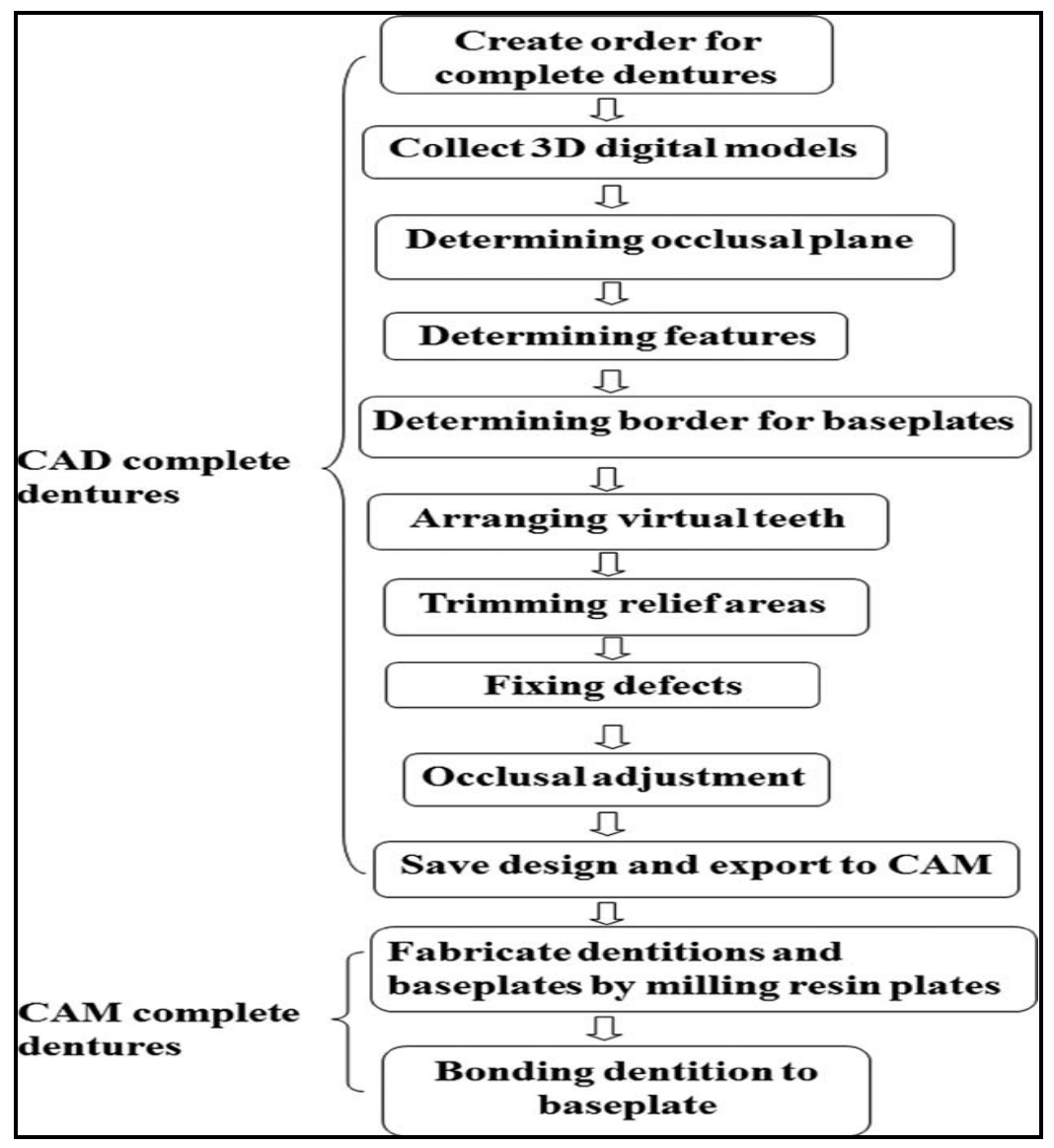

Figure(16): The flowchart for designing and fabricating complete dentures via CAD/CAM technology. $\mathrm{CAD}=$ computer-aided design, $\mathrm{CAM}=$ computer aided manufacturing. ${ }^{(56)}$ 
Han et al. in 2017 explained that removable complete dentures were successfully can be designed using the computerized software through many steps including generation of 3D digital edentulous models, analysis of models, arrangement of upper and lower artificial teeth, and occlusal records. Artificial dentitions and baseplates were successfully constructed according to the designed complete dentures using milling machine controlled by a CAM software. Bonding artificial dentitions to the underlying baseplates produce the finished complete dentures. ${ }^{(56)}$

The development in the clinical procedures that register the required morphology, the prototype three dimensional artificial teeth arrangement program indicates that $\mathrm{CAD}$ programs can be developed when artificial teeth are arranged practically as part of the CADCAM complete dentures. ${ }^{(59)}$

\section{D- CAD-CAM technology in fabrication of an implant surgical guides:}

A surgical guides fabrication was made from stainless steel for the placement of dental implants to retain prosthesis was described by (Bibb et al., 2009) It is firstly reported using a SLM technology to manufacture a custom-fitting surgical guides. ${ }^{(60)}$

\section{E- CAD-CAM technology in the fabrication of maxillofacial prosthesis :}

CAD/CAM technology is popularly used for the production of maxillofacial prosthesis like artificial (ear, nose, eye), individual respiratory masks, extra-oral radiation devices, facial protection devices or even in the production of a resin model with lithographic technique, then wax pattern is made by the use of CAD software, a three dimensional (3-D) surfaces of an object are obtained. Digital data is managed within the computer and prosthesis is milled by milling machine controlled by computer. A silicone material is the material of choice used for the fabrication of maxillofacial prosthesis. ${ }^{(21)}$ The benefit of CAD/CAM technology is time saving, durable and not need skilled technician to sculpt a wax pattern. ${ }^{(61)}$

Ciocca et al. in 2007 described a method to fabricate maxillofacial prosthesis retained by implant by using CAD-CAM system and a rapid prototyping machine with many advantages including: 1) A threedimensional image of the defective surface through digitalization and create a mirror image of the normal ear. 2) It is not necessarily to take an impression of the defective side only the correct position of the implants were recorded to make the bar for retaining the prosthesis. 3) Eliminating the need for the wax pattern. 4) No need for stone model because of a rapid prototyping process. ${ }^{(62)}$

\section{- Advantages of CAD/CAM systems ${ }^{(1,21)}$}

1. Chair-side restoration was produced and finished within one visit in office system. 
2. High precision and accuracy for making possible restorations and appliances created on digital models.

3. Restorations were finished with high quality, well design, and easily insertion process.

4. No need for the laboratory conventional lost wax method.

5. Reduce the use of traditional impression methods through designing and machining different restorations with the help of computer.

6. Opportunity to view occlusion.

7. Cross-infection control in the dental / lab fields.

\section{- Disadvantages of CAD/CAM technique:}

1. High cost of the technique.

2. Time consuming from start to finish the steps of the technique.

3. It is somewhat difficult to incorporate esthetic veneers with strong cores and frameworks. ${ }^{(5)}$

4. Using chair side CAD-CAM technique needs more time by the dentist within the clinic and the cost is at least twice than for conventional restoration using lab services. ${ }^{(1)}$

\section{CONCLUSION}

In this reviewed article, we explained the development, stages, and application of dental CAD-CAM systems. Dental CAD-CAM systems were applied in the production of crowns, bridges, inlays, onlays, veneers, implant, maxillofacial prosthesis, RPDs and others. The success of the restoration is more influenced by the results of the scanning procedure, data processing, and successful milling rather than the increase in the processing axes numbers of milling devices.

\section{REFERENCES}

1. Dwivedi TN, Jakhanwal I, Anupama T, Singh Gill G, Narang A, Bhatheja A. CAD CAM in Prosthetic Dentistry: A Comprehensive Review. Int $J$ Commu Health Medic Res. 2017; Vol.3 (2):56-59.

2. Davidowitz G, Kotick PG. The use of CAD/CAM in dentistry. Dent Clin North Am. 2011;55(3): 559-570.

3. Miyazaki T, Hotta Y. CAD/CAM systems available for the fabrication of crown and bridge restorations. Aust Dent J . 2011 June;56 Suppl 1:97-106.

4. Rekow ED, Silva NR, Coelho PG, Zhang Y, Guess P, Thompson VP. Performance of dental ceramics: challenges for improvements. J Dent Res. 2011 Aug; 90(8): 937-52.

5. Uzun G. An overview of dental CAD/CAM systems. Biotechnol \& Biotechnol Eq. 2008;22(1):530-535.

6. Raigrodski AJ, Chiche GL. The safety and efficiency of anterior ceramic fixed partial dentures: a review of the literature. $J$ Prosthet Dent. 2001; 86: 520-525.

7. Raigrodski AJ. Contemporary materials and technologies for all-ceramic fixed partial dentures: A review of the literature. $J$ Prosthet Dent. 2004; 92: 557-562. 
8. Mormann WH, Brandestini M, Lutz F Barbakow F. Chair side computer-aided direct ceramic inlays. Quintessence Int.1989; 20: 329-339.

9. Hikita K, Uchiyama Y. Studies on three dimensional measurement and restoration of tooth crown form by CAD/CAM. $J$ Jpn Prosthondont Soc. 1989; 33(S82):142.

10. Marras I, Nikolaidis N, Mikrogeorgis G, Lyroudia K, Pitas I. A virtual system for cavity preparation in endodontics. $J$ Dent Educ. 2008 Aprl;72(4):494-502.

11. Susic I, Travar M, and Susic M. The application of CAD / CAM technology in Dentistry. Mater Scie and Engine. 2017. 200:1-12.

12. Duret F, Preston JD. CAD/CAM imaging in dentistry. Curr Opin Dent. 1991; 1: 150154.

13. Andersson M, Oden A. A new all-ceramic crown: a dense-sintered, high purity alumina coping with porcelain. Acta Odontol Scand. 1993; 51: 59-64.

14. Andersson M, Carlsson L, Persson M, Bergmann B. Accuracy of machine milling and spark erosion with a CAD/CAM system. J Prosthet Dent. 1996; 76: 187193.

15. Aoki H, Fujita T, Nishina T. CAD system and $\mathrm{NC}$ construction for the automation of dental laboratory. J Dent Technolog. 1986; 14: $1495-1526$.
16. Tsutsumi S, Fukuda S, Tani Y. 3-D image measurements of teeth and alveolar ridge. JDR. 1989; 68(Sp.): 924.

17. Kimura H, Sohmura T, Watanabe T. Three dimensional shape measurement of teeth (part 1) Measurement by meanns of high precision laser displacement meter. $J$ Dent Mater. 1988; 7: 552- 557.

18. Kimura H, Kawanaka M, Watanbe T, Takahashi J, An H, Omura K. An approach to dental CAD/CAM (part 1) Measurement of coronal figure. J Dent Mater. 1988; 7: 413-418.

19. Sneha S. Mantri and Abhilasha S. Bhasin. CAD/CAM IN DENTAL RESTORATIONS: AN OVERVIEW. Annals and Essences of Dentistry.2010. Vol $2:$ : (3) :123-128.

20. Beuer F, Schweiger J, and Edelhoff D. Digital dentistry: an overview of recent developments for CAD/CAM generated restorations. Brit Dent J.2008 Vol.204 (9):505-511.

21. Tamrakar AK, Rathee M, Mallick R, Dabas S. CAD/CAM IN PROSTHODONTICS - A FUTURISTIC OVERVIEW. Annals of Dental Specialty.2014; Vol. 2(1):14-15

22. May K B, Russell M M, Razzoog M E, Lang B R. Precision of fit: the Procera All Ceram crown. J Prosthet Dent. 1998; 80: 394-404.

23. Webber B, McDonald A, Knowles J. An in vitro study of the compressive load at fracture of Procera All Ceram crowns with 
varying thickness of veneer porcelain. $J$ Prosthet Dent. 2003; 89: 154-160.

24. Reiss B, Walther W. Clinical long-term results and 10-year Kaplan-Meier analysis of Cerec restorations. Int J Comput Dent. 2000; 3: 9-23

25. Nakamura $\mathrm{T}$, Dei $\mathrm{N}$, Kojima $\mathrm{T}$, Wakabayashi K. Marginal and internal fit of Cerec 3 CAD/CAM all ceramic crowns. Inter J Prosthodontics. 2003; 16: 244-248.

26. Effrosyni A, Tsitrou E, Northeast S, van Noort R. Evaluation of the marginal fit of three margin designs of resin composite crowns using CAD/CAM. J Dent. 2007; 35: 68-73.

27. Miyazaki T, Hotta Y, Suzuki E, Miyaji T, Takahashi H, Furuya R, Kawawa T. An Approach to the dental CAD/CAM using the electric discharge machining(Part 1) Measurement of coronal figure, computer graphics, and CAD procedure. J Showa Univ Dent Soc. 1991; 11: 65-69.

28. Miyazaki T, Kitamura M, Inamoti $\mathrm{T}$, Suzuki E,Miyaji T, Takahashi H, Furuya R, Kawawa T. An approach to the dental CAD/CAM using the electric discharge machining (Part2) development of the three dimensional multi-functional NC machine and the machining properties by the ram type EDM in di ionized water. J Showa Univ Dent Soc. 1991; 11:70-77.

29. Miyazaki T, Hotta Y, Kitamura M, Suzuki E, Miyaji T, Takahashi H, Furuya R, Kawawa T. An approach to the dental
CAD/CAM using the electric discharge machining (Part 3) An approach to the fabrication of electrode for the ram type electric discharge machining using the NC milling technique. J Showa Univ Dent Soc. 1991; 11: 78-83.

30. Miyazaki T, Kitamura M, Inamoti $\mathrm{T}$, Suzuki E, Miyaji T, Takahashi H, Furuya R, Kawawa T. An approach to the dental CAD/CAM using the Electric discharge machining (Part 4) Fabrication of male and female of the telescope denture by the NC wire type electric discharge machining. $J$ Showa Univ Dent Soc. 1991; 11: 84-88.

31. Hotta Y. Fabrication of titanium copings using the CAD/CAM process. J Dent Mat Dev. 1992; 11: 169-178.

32. Miyazaki T, Hotta Y, Kunii J, Kuriyama $S$ and Tamaki Y. A review of dental CAD/CAM: current status and future perspectives from 20 years of experience. Dent Mater J. 2009;28(1): 44-56.

33. Lucas LC, Lemons JE. Biodegradation of restorative metallic systems. Adv Dent Res. 1992; 6: 32-37

34. Sorensen LA, Knode H, Torres TJ. Inceramall ceramic bridge technology. Quintessence Dent Technol. 1992; 15: 4146

35. Sorensen JA, Kang SK, Torren TJ, Knode H. In-Ceram fixed partial dentures: threeyear clinical trialresults. J Calif Dent Assoc. 1998; 26: 207-214 
36. Sorensen JA, Cruz M, Mito WT, Raffeiner O,Meredith HR, Foser HP. A clinical investigation onthree-unit fixed partial dentures fabricated with alithium disilicate glass-ceramic. Pract Periodontics Aethet Dent. 1999; 11: 95-106

37. Tinschert J, Zwez D, Marx R, Anusavice KJ.Structual reliability of alumina-, feldspar-, leucite,mica-and zirconia-based ceramics. J Dent. 2000; 28:529-535

38. Tinschert J, Natt G, Mautsch W, Augthun M,Spiekermann H. Fracture resistance of lithiumdisilicate-, alumina-, and zirconiabased three-unitfixed partial dentures: a laboratory study. Int J Prosthodont. 2001; 14: 231-238.

39. Vult von Steyern P, Jonsson O, Nilner K. Five yearevaluation of posterior all-ceramic three -unit (In-Ceram) FPDs. Int $J$ Prosthodont. 2001; 14: 379-384.

40. Olsson KG, Furst B, Andersson B, Carlsson GE. Along-term retrospective and clinical follow-up studyof In-Ceram Alumina FPDs. Int I Prosthodont. 2003; 16: 150156.

41. Suarez MJ, Lozano JF, Paz Salido M, Martinez F.Three-year clinical evaluation of In-Ceram Zirconia posterior FPDs. Int $J$ Prosthodont. 2004; 17: 35-38.

42. Esquivel-Upshaw JF, Anusavice KJ, Young H, JonesJ, Gibbs C. Clinical performance of Lithia disilicate based core ceramic for three-unit posterior FPDs. Int $J$ Prosthodont. 2004; 17: 469-475.
43. Oden A, Andersson M, Krystek-Ondracek I,Magnusson D. Five-year clinical evaluation of Procera All Ceram crowns. $J$ Prosthet Dent. 1998; 80:450-456.

44. Att W, Kurun S, Gerds T, Strub JR. Fracture resistance of single-tooth implant supported all-ceramic restorations after exposure to the artificial mouth. J Oral Rehabil. 2006;33(5):380-386.

45. Att W, Kurun S, Gerds T, Strub JR. Fracture resistance of single-tooth implant supported all-ceramic restorations: an in vitro study. J Prosthet Dent. 2006; 95(2):111-116.

46. Kiliaridis S, Kjellberg $\mathrm{H}$, Wenneberg B, Engström C. The relationship between maximal bite force, bite force endurance, and facial morphology during growth. A cross-sectional study. Acta Odonto logica Scandinavica. 1993;51(5):323-331.

47. Kokubo Y, Tsumita M, Sakurai S, Torizuka K, Vult Von Steyern P, Fukushima S. The effect of core framework designs on the fracture loads of all-ceramic fixed partial dentures on posterior implants. J Oral Rehabil. 2007;34(7):503-507.

48. Williams RJ, Bibb R, Eggbeer D et al. Use of CAD/CAM technology to fabricate a removable partial denture framework. $J$ Prosthet Dent. 2006;96(2):96-99.

49. Tan PL, Gratton DG, Diaz-Arnold AM, Holmes DC. An in vitro comparison of vertical marginal gaps of CAD/CAM 
titanium and conventional cast restorations.

J Prosthodont. 2008;17(5):378-383.

50. Thompson WB, Owen JC, De SG, Stark SR, Henderson TC. Feature-based reverse engineering of mechanical parts. IEEE Transactions on Robotics and Automation. 1999;15(1):57-66.

51. Persson A, Andersson M, Oden A Sandborgh-Englund G. A three-dimensional evaluation of a laser scanner and a touchprobe scanner. $J$ Prosthet Dent. 2006;95(3):194-200.

52. Ender A, Mörmann WH, Mehl A. Efficiency of a mathematical model in generating CAD/CAM-partial crowns with natural tooth morphology. Clinic Oral Inves. 2011;15(2):283-289.

53. Mehl A, Blanz V, Hickel R. Biogeneric tooth: A new mathematical representation for tooth morphology in lower first molars. Euro J Oral Scien. 2005;113(4):333-340.

54. Grossmann Y, Pasciuta M, and Finger I M. A novel technique using a coded healing abutment for the fabrication of a CAD/CAM titanium abutment for an implant-supported restoration. J Prosthet Dent. 2006;95:258-61.

55. Cunha TR, Della Vecchia MP, Regis RR, et al. A randomized trial on simplified and conventional methods for complete denture fabrication: masticatory performance and ability. J Dent. 2013;41:133-142.

56. Han W, Li Y, Zhang Y, lv Y, Zhang Y, Hu P, Liu H, Ma Z, Shen Y. Design and fabrication of complete dentures using CAD/CAM technology. J Med. 2017,96:18.

57. Infante L, Yilmaz B, McGlumphy E, et al. Fabricating complete dentures with CAD/CAM technology. J Prosthet Dent. 2014;111:351-355.

58. Bidra AS, Taylor TD, Agar JR. Computeraided technology for fabricating complete dentures: systematic review of historical background, current status, and future perspectives. $J$ Prosthet Dent. 2013;109:361-6.

59. Charles J. Goodacre, Antoanela Garbacea, W. Patrick Naylor, Tony Daher, Christopher B. Marchack, and Jean Lowry. CAD/CAM fabricated complete dentures: concepts and clinical methods of obtaining required morphological data. J Prosthet Dent. 2012;107:34-46.

60. Bibb R, Eggbeer D, Evans P et al. Rapid manufacture of custom-fitting surgical guides. Rapid Protot J. 2009;15(5):346354.

61. Jiao T, Zhang F, Huang X, Wang C. Design and Fabrication of Auricular Prostheses by CAD/CAM System. Int J Prosthodont. 2004.17:406-463.

62. Ciocca L, Mingucci R, Gassino G, and Scotti R. CAD/CAM ear model and virtual construction of the mold. J Prosthet Dent. 2007; 98:339-343. 